\title{
Rancang Bangun Perangkat Kendali ROV Berbasis Joypad Dan Aplikasi Pemantauan Kondisi Bawah Air Berbasis Video Streaming
}

\author{
${ }^{1}$ Yogi aldino,${ }^{2}$ Sri Ratna Sulistiyanti, ${ }^{3}$ M. Komarudin, ${ }^{4}$ Helmy Fitriawan \\ Jurusan Teknik Elektro Universitas Lampung \\ Jalan Prof. Soemantri Brojonegoro No.1 Bandar Lampung 35145 \\ ${ }^{1}$ yogialdino@gmail.com, \\ ${ }^{2}$ sriratnasulistiyantiegmail.com, \\ ${ }^{3}$ mkomarudineunila.ac.id
}

\begin{abstract}
Intisari - ROV merupakan sebuah robot penjelajah bawah air yang dikendalikan oleh operator menggunakan sistem pengendali ROV dengan perangkat remote control. Pada penelitian ini digunakan perangkat remote control berupa Joypad yang telahdiintegrasikan denganJoypad dan mikrokontroler Arduino Pro Mini.ROV dilengkapi dengan Raspberry Pi, kamera, sensor suhu, sensor gyroscope, sensor tegangan dan sensor tekanan air untuk mengakuisisi data kondisi bawah air untuk kemudian dikirimkan ke laptop operator dan kemudian ditampilkanpada sebuah aplikasi pemantauan berupa GUI (Graphic User Interface) yang dibangun denganbahasa pemrograman Python 2.7. Hasil pengujian diperoleh bahwa GUI dapat memantau kondisi bawah air dengan menampilkan video streaming, data suhu, dan kedalaman ROV secara realtime. Perangkat kendali pada ROVmampu mengendalikan laju pergerakan ROV untuk turun, naik, belok kanan, belok kiri, maju dan mundur tanpa adanya halangan pada kedalaman 0 meter $-4,2$ meter dengan jangkauan radius 20 meter.
\end{abstract}

Kata kunci - ROV, Aplikasi Pemantauan, Sistem Kendali ROV, Joypad, Phyton 2.7.

Abstract - ROV is an underwater explorer robot that is controlled by the operator using the ROV controller system with a remote control device. In this study a remote control device in the form of Joypad was integrated with Joypad and Arduino Pro Mini microcontrollers. The ROV is equipped with Raspberry Pi, cameras, temperature sensors, gyroscope sensor, voltage sensor and water pressure sensors to acquire underwater conditions to be sent to the operator's laptop and the displayed on an monitoring application in the form of a GUI (Graphic User Interface) built in Python 2.7 programming. The test results are obtained that the GUI can monitor underwater conditions by displaying video streaming, temperature data, and ROV depth in realtime. Control devices in the ROV are able to control the movement of the ROV to go down, up, turn right, turn left, forward and backward without any obstacles at a depth of 0 meters - 4.2 meters with a radius range of 20 meters.

Keywords - ROV, Monitoring Aplication, ROV Control System, Joypad, Phyton 2.7. 


\section{PENDAHULUAN}

Berdasarkan data dari kementrian kelautan dan perikanan republik indonesia, indonesia adalah negara kepulauan dengan wilayah daratan dan perairan (airan) dengan luas $5.193 .250 \mathrm{~km} 2$. Wilayah perairan indonesia memiliki luas kurang lebih $3.273 .810 \mathrm{~km} 2$ atau sekitar dua per tiga luas dari keseluruhan luas negara indonesia. Kondisi airan indonesia meliputi unsur-unsur seperti kondisi fisik, ekosistem dan suhu perlu dipantau untuk menjaga sumber daya air yang berpotensi menimbulkan bencana alam, kerusakan ekosistem air ataupun keamanan nasional (souhoka, 2013).

Teknologi yang dapat digunakan dalam proses pemantauan kondisi bawah air adalah rov atau remotely operated vehicle. Rov merupakan sebuah robot penjelajah bawah air yang dikendalikan oleh operator menggunakan sistem pengendali rov dengan perangkat remote control berupa Joypad (christ, 2014). Rov tersebut dapat dilengkapi kamera, sensor suhu, dan tekanan air untuk mengakuisisi data kondisi bawah air dan kemudian dikirimkan ke laptop operator untuk diolah lebih lanjut.

Video stream, data suhu, dan tekanan air rov yang diterima oleh laptop operator akan diolah menjadi video yang memuat data suhu dan tekanan yang kemudian ditampilkan ke monitor laptop dengan menggunakan aplikasi pemantauan bawah air menggunakan gui berbasis bahasa pemrograman python 2.7 secara realtime.

\section{METODOLOGI PENELITIAN}

\section{A. Diagram Alir Penelitian}

Perancangan penelitian ini, langkahlangkah kerja yang dilakukan dengan beberapa metode merujuk pada Diagram Alir Penelitian pada Gambar 1.

\section{B. Diagram Blok Perancangan Sistem Model}

Rancangan keseluruhan sistem pada penelitian ini merujuk pada Gambar 2.

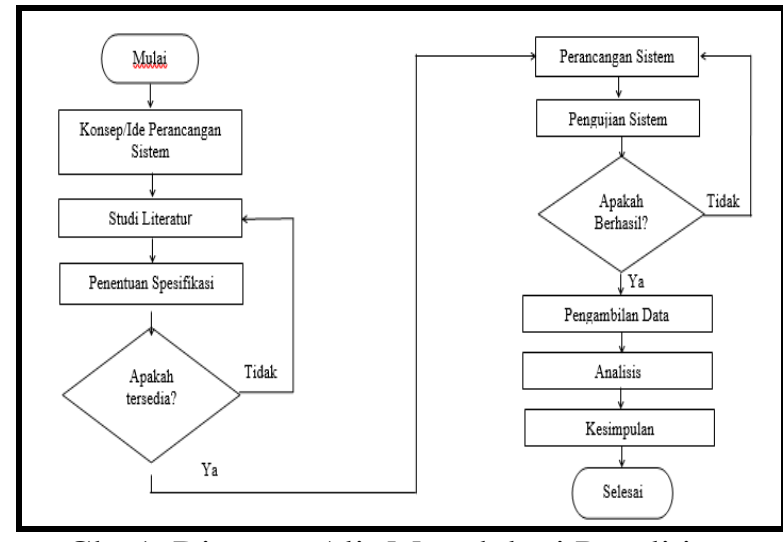

Gbr 1. Diagram Alir Metodologi Penelitian

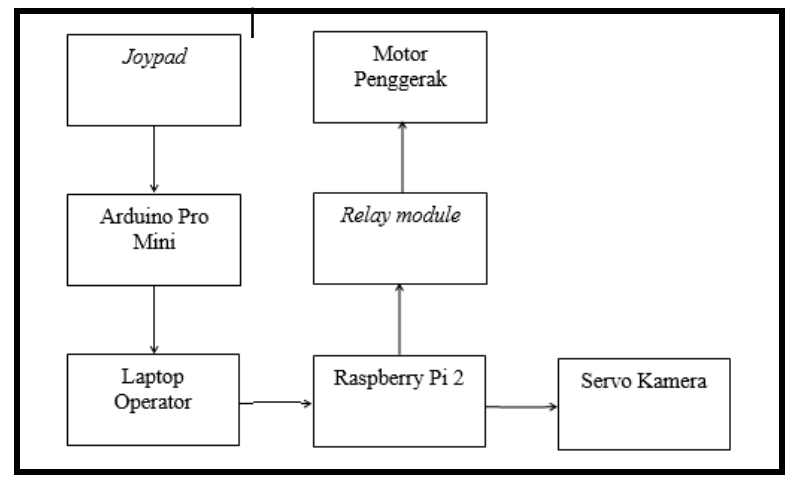

Gbr 2. Perancangan Model Sistem

Gambar 2 menjelaskan alir sistem pengendalian ROV dengan menggunakan Joypad sebagai input, motor penggerak dan servo kamera sebagai output yang dihasilkan. Joypad digunakan sebagai input dengan tujuan memberikan instruksi pada tomboltombolnya menuju Arduino Pro Mini untuk diolah menjadi instruksi dengan format string dan dikirimkan menuju Laptop Operator. Instruksi pada Joypad yang telah diolah tersebut, kemudian dikirimkan menuju Raspberry Pi 2 agar Raspberry Pi 2 dapat mengendalikan motor penggerak dan servo kamera.

\section{Perancangan Model ROV}

Perancangan ROV ini berfungsi untuk mengatur laju empat motor pada ROV agar dapat bergerak maju, mundur, naik, turun, berbelok dan kombinasi gerakan lainnya. 


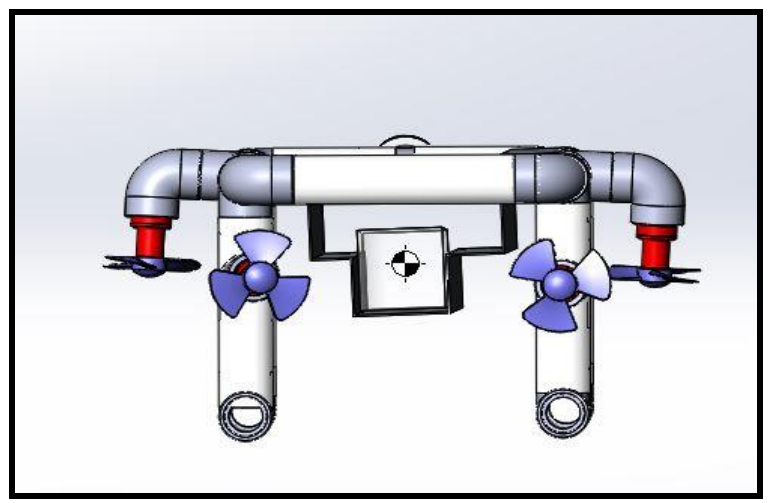

Gbr 3. Perancangan Model ROV

Pada Gambar 3, Motor-motor tersebut disambungkan dengan propeller yang berbeda-beda, yakni jenis CW (Counter Wise atau searah jarum jam) dan CCW (Counter Clock Wise atau berlawanan arah jarum jam). Propeller jenis CW disambungkan pada motor 1 dan 3, sedangkan CCW pada motor 2 dan 4.

\section{Perancangan Aplikasi Pemantauan Kondisi Bawah Air}

Sebuah aplikasi pemantauan dibuat untuk memantau pergerakan ROV dan juga kondisi di bawah air. Aplikasi ini akan menampilkan data waktu, tegangan, pitch, roll, dan kedalaman, serta video live streaming yang akan ditampilkan pada GUI berbasis Python 2.7.

1) Raspberry Pi

Raspberry $\mathrm{Pi}$ sering juga disingkat dengan nama Raspi adalah komputer papan tunggal (Single Board Circuit) dengan ukuran yang relatif kecil. Raspberry $\mathrm{Pi}$ merupakan pengembangan dari Rasberry Pi Foundation yang digawangi oleh ahli komputer dari Universitas Cambridge, Inggris (Raspberry Pi Foundation, 2016).

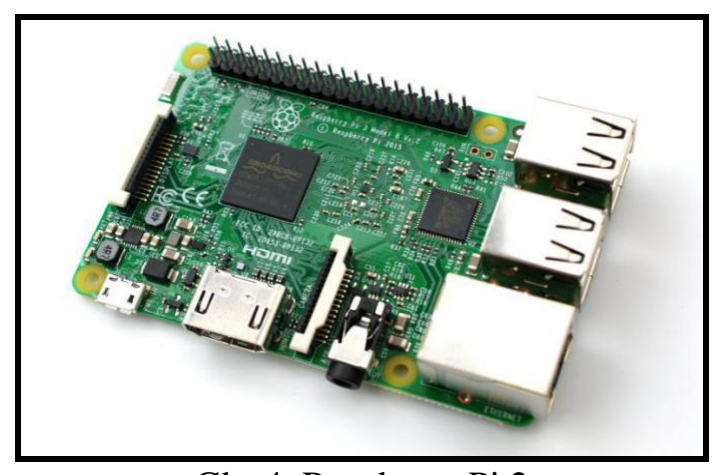

Gbr 4. Raspberry Pi 2
Raspberry Pi memiliki pin generic yang memiliki fitur-fitur seperti pin antarmuka I2C, pin PWM (Pulse Width Modulation) dan pin serial $\mathrm{Tx}$ dan $\mathrm{Rx}$ sehingga dapat menghubungkan hardware ke Raspberry untuk keperluan tertentu (YeffriHandoko, 2013).

Raspberry $\mathrm{Pi} 2$ digunakan untuk mengumpulkan data-data sensor suhu, sensor tekanan, sensor gyroscope, sensor tegangan dan video streaming yang ditangkap oleh kamera pada ROV.

2) Pemrograman Python 2.7

Python adalah Bahasa pemrograman yang bersifat interpreter dan dapat beroperasi di hamper semua platform, seperti keluarga Linux/Unix, Mac, Windows, dan lainnya (Rosmala, 2012).

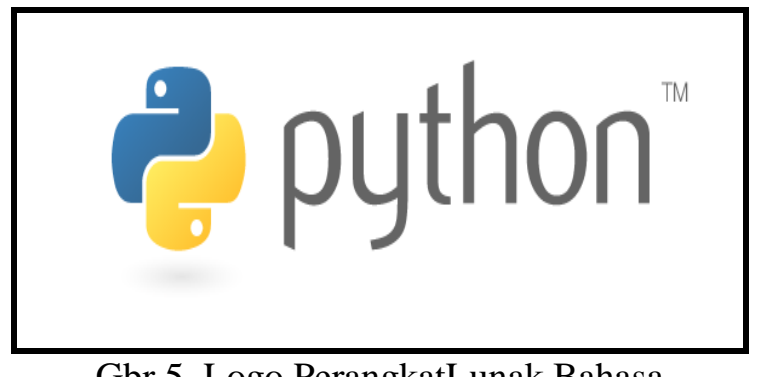

Gbr 5. Logo PerangkatLunak Bahasa Pemrograman Python

Sedangkan, pada pengembangan GUI (Graphical User Interface) pada desktop, Python menyediakan pustaka - pustaka pengembangan untuk desktop, seperti Tk, Wx Widgets, GTK+, Qt, kelas-kelas dari Microsoft Foundation melalui perluasanperluasan win32, Delphi (Berkah Santoso, 2012).

Pemrograman Python 2.7 dipasang pada Raspberry 2 yang telah terhubung dengan sensor suhu, sensor tekanan, sensor Gyroscope dan kamera. Pemrograman Python 2.7 digunakan untuk mengirimkan data-data sensor menuju laptop operator. Pada laptop operator juga dipasang Pemrograman Python 2.7 untuk membangun GUI (Graphic User Interface) agar dapat menampilkan data-data sensor dan video streaming. 
3) Listing Program Aplikasi Pemantauan KondisiBawah Air

Aplikasi pemantauan kondisi bawah air dibuat dengan Bahasa Pemrograman Python 2.7 dengan tambahan library GUI Tkinter untuk menampilkan tampilan aplikasi pemantauan yang terdiri dari frame untuk menampilkan video dan frame untuk menampilkan data dan tombol UX (User Experience)

\begin{tabular}{|l|}
\hline import numpy as np \\
import cv2 \\
import Tkinter as tk \\
import Image, ImageTk \\
import datetime \\
import tkMessageBox \\
import Qs \\
import socket \\
import sys \\
import time \\
import re \\
import threading \\
from threading import Thread \\
..... \\
..... \\
..... \\
window.mainloop()
\end{tabular}

Gbr 6. Listing Pemrograman Aplikasi Pemantauan Kondisi Bawah Air (GUI)

Listing Program terdiri dari beberapa fungsi yang terdiri dari penciptaan GUI, penyedia jalur komunikas untuk menerima live streaming video dan data-data sensor dari Raspberry Pi 2 pada ROV, dan menyimpan data-data sensor dalam format excel.

\section{E. Perancangan Sistem Perangkat Kendali ROV}

Sistem perangkat kendali ROV berbasis Joypad ini akan memberikan perintah kendali pada ROV melalui tombol yang ditekan pada Joypad. Joypad yang digunakan adalah sebuah controller PS2 (Playstation 2), kemudian diintegrasikan dengan Arduino Uno yang terhubung pada laptop. Arduino Uno digunakan untuk mengubah fungsi perintah tombol-tombol pada Joypad menjadi data string yang kemudian dikirimkan dari laptop menuju Raspberry pada ROV.

\section{1) Joypad}

Joypad biasa digunakan untuk memberikan instruksi-intruksi khusus di tiap tombolnya pada console video game PS2 (Playstation2).Joypad sendiri menggunakan komunikasi SPI (Serial Peripheral Interface) (Zaenurrohman, 2014).

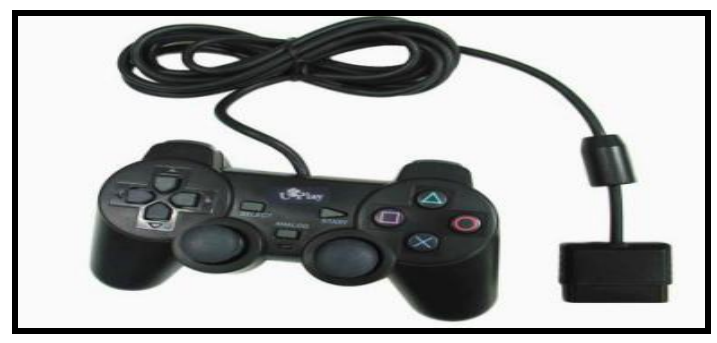

Gbr 6 Joypad

2) Arduino Pro Mini

Arduino Pro Mini adalah mikrokontroler yang berbasis IC ATmega328 dengan jumlah pin digital I/O sebanyak 14 buah (termasuk 6 buah pin dengan konfigurasi PWM) (Anonim Arduino Pro Mini, 2016).

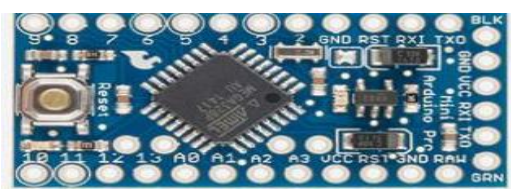

Gbr 7 Arduino Pro Mini

3) Listing Program Perangkat Kendali ROV

Pengujian Joypad membutuhkan program menggunakan Bahasa Pemrograman Python 2.7 agar dapat membaca data serial yang dikirim oleh Arduino. Pemrograman tersebut membutuhkan library serial agar Python 2.7 dapat berkomunikasi dengan Arduino dengan menggunakan Protokol USB.

\begin{tabular}{|l|} 
import socket \\
import serial \\
import sys \\
import os \\
$\ldots \ldots$ \\
$\ldots \ldots$ \\
try: \\
$\ldots \ldots \ldots$ \\
except: \\
pass \\
secksclose \\
\hline
\end{tabular}

Gbr 8 Listing Pemrograman Perangkat Pengendali ROV 
Bahasa pemrograman Python 2.7 digunakan untuk menguji proses pengujian Joypad agar dapat dikombinasikan dengan listing program GUI.

\section{4) Instruksi Perangkat Kendali ROV Pada Joypad}

Sistem perangkat kendali ROV berbasis Joypad in iakan memberikan perintah kendali pada ROV melalui tombol yang ditekan pada Joypad. Joypad yang digunakan adalah sebuah controller PS2 (Playstation 2), kemudian diintegrasikan dengan Arduino Uno yang terhubung pada laptop. Arduino Uno digunakan untuk mengubah fungsi perintah tombol-tombol pada Joypad menjadi data string yang kemudian dikirimkan dari laptop menuju Raspberry pada ROV. Joypad pada perangkat kendali ROV akan memberi perintah seperti pada Tabel 1.

Tabel 1. Instruksi Perangkat Kendali Pada Joypad

\begin{tabular}{|c|c|c|}
\hline No & Tombol & Perintah \\
\hline 1 & Kotak & Mundur \\
\hline 2 & Segitiga & Naik \\
\hline 3 & Bulat & Turun \\
\hline 4 & Silang & Maju \\
\hline 5 & Panah Atas + Silang & Maju dan Naik \\
\hline 6 & $\begin{array}{c}\text { Panah Bawah + } \\
\text { Silang }\end{array}$ & Maju dan Turun \\
\hline 7 & Panah Kiri + Silang & $\begin{array}{c}\text { Maju dan Berbelok ke } \\
\text { Kiri }\end{array}$ \\
\hline 8 & $\begin{array}{c}\text { Panah Kanan + } \\
\text { Silang }\end{array}$ & $\begin{array}{c}\text { Maju dan Berbelok ke } \\
\text { Kanan }\end{array}$ \\
\hline 9 & Panah Atas + Kotak & Mundur dan Naik \\
\hline 10 & $\begin{array}{c}\text { Panah Bawah + } \\
\text { Kotak }\end{array}$ & Mundur dan Turun \\
\hline 11 & Panah Kiri + Kotak & $\begin{array}{c}\text { Mundur dan Berbelok ke } \\
\text { Kiri }\end{array}$ \\
\hline 12 & Panah Kanan + Kotak & $\begin{array}{c}\text { Mundur dan Berbelok ke } \\
\text { Kanan }\end{array}$ \\
\hline 13 & $\mathrm{R} 1$ & Servo Kamera ke Atas \\
\hline 14 & $\mathrm{R} 2$ & Servo Kamera ke Bawah \\
\hline 15 & L1 & Servo Kamera ke Kiri \\
\hline 16 & L2 & Servo Kamera ke Kanan \\
\hline
\end{tabular}

\section{PENGUJIAN DAN ANALISIS}

\section{A. Pengujian Aplikasi Pemantauan Kondisi Bawah Air}

Time conn menampilkan waktu yang telah digunakan selama ROV aktif dan koneksi antara Raspberry pi dan laptop turut aktif. VPF menunjukkan besar video per frame, yang mana menampilkan waktu proses dari video per frame

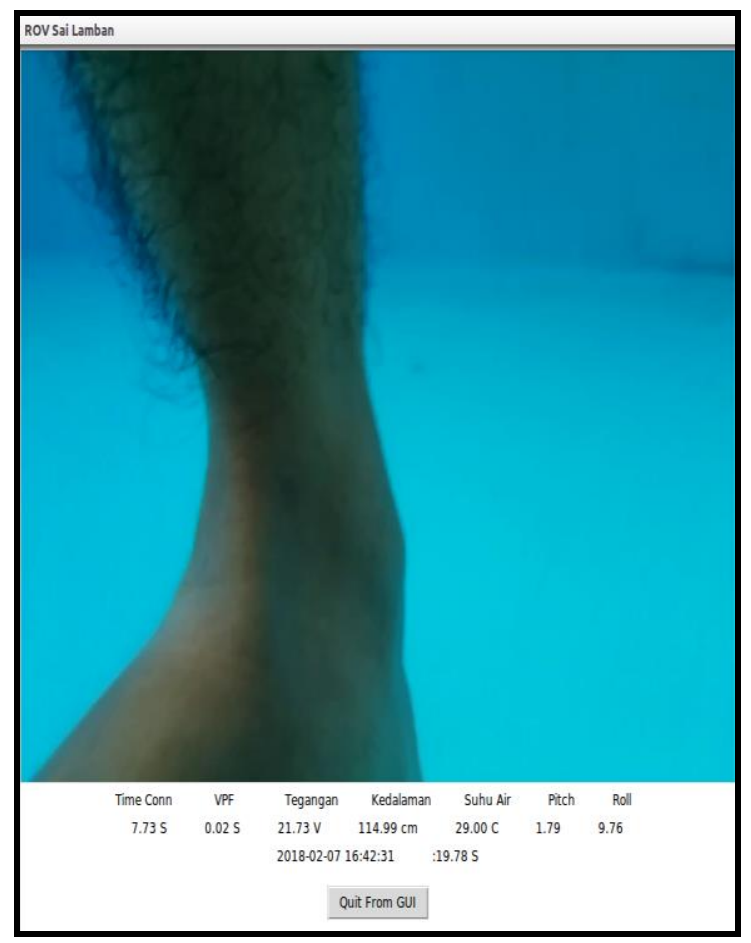

Gbr 9 Pengujian Joypad dan Arduino

Tegangan menunjukkan besar tegangan yang dibaca oleh sensor tegangan yang dipasang pada aki sebagai catu daya ROV. Kedalaman dan suhu air menunjukkan kedalaman dan suhu air yang dibaca oleh sensor suhu dan sensor tekanan. Pitch dan Roll menunjukkan hasil Pitch dan Roll yang dibaca oleh sensor MPU6050. Waktu yang ditampilkan pada bagian bawah aplikasi menunjukkan waktu pada saat ROV aktif digunakan. Hasil dari aplikasi ini kemudian akan disimpan dalam bentuk file excel $\left({ }^{*} \mathrm{csv}\right)$. Pada pengujian ini data sensor berhasil dikirimkan dan ditampilkan pada aplikasi dengan baik, dan sesuai dengan data sensor yang dikriimkan pada serial monitor Raspberry Pi. Hasil video streaming yang dikirimkan juga mampu tayang dengan baik tanpa adanya delay. 
Tabel 2. Data Tersimpan Aplikasi Pemantauan Kondisi Bawah Air

\begin{tabular}{|c|c|c|c|c|c|}
\hline Waktu & Tegangan & Kedalaman & Suhu & Pitch & Roll \\
\hline $\begin{array}{l}2017-12-13 \\
17: 01: 29\end{array}$ & $14.77 \mathrm{~V}$ & $1.18 \mathrm{~cm}$ & $\begin{array}{c}30.00 \\
\mathrm{C}\end{array}$ & 1.19 & 0.11 \\
\hline $\begin{array}{l}2017-12-13 \\
17: 01: 29\end{array}$ & $14.89 \mathrm{~V}$ & $5.83 \mathrm{~cm}$ & $\begin{array}{c}30.00 \\
\mathrm{C} \\
\end{array}$ & 0.49 & 0.80 \\
\hline $\begin{array}{l}2017-12-13 \\
17: 01: 30\end{array}$ & $14.89 \mathrm{~V}$ & $8.18 \mathrm{~cm}$ & $\begin{array}{c}30.00 \\
\mathrm{C}\end{array}$ & 1.36 & 0.08 \\
\hline $\begin{array}{l}2017-12-13 \\
17: 01: 31\end{array}$ & $15.64 \mathrm{~V}$ & $15.14 \mathrm{~cm}$ & $\begin{array}{c}30.00 \\
\mathrm{C}\end{array}$ & 2.67 & 0.70 \\
\hline $\begin{array}{l}2017-12-13 \\
17: 01: 32\end{array}$ & $14.94 \mathrm{~V}$ & $20.97 \mathrm{~cm}$ & $\begin{array}{c}30.00 \\
\text { C }\end{array}$ & 2.74 & 0.46 \\
\hline $\begin{array}{l}2017-12-13 \\
17: 01: 32 \\
\end{array}$ & $14.89 \mathrm{~V}$ & $30.28 \mathrm{~cm}$ & $\begin{array}{c}30.00 \\
\mathrm{C} \\
\end{array}$ & 1.24 & 0.41 \\
\hline $\begin{array}{l}2017-12-13 \\
17: 01: 33\end{array}$ & $14.34 \mathrm{~V}$ & $43.07 \mathrm{~cm}$ & $\begin{array}{c}30.00 \\
\mathrm{C} \\
\end{array}$ & 3.09 & 2.91 \\
\hline $\begin{array}{l}2017-12-13 \\
17: 01: 34\end{array}$ & $14.96 \mathrm{~V}$ & $47.72 \mathrm{~cm}$ & $\begin{array}{c}30.00 \\
\mathrm{C}\end{array}$ & 2.53 & 1.16 \\
\hline $\begin{array}{l}2017-12-13 \\
17: 01: 35\end{array}$ & $14.89 \mathrm{~V}$ & $57.02 \mathrm{~cm}$ & $\begin{array}{c}30.00 \\
\mathrm{C}\end{array}$ & 10.41 & 3.46 \\
\hline $\begin{array}{l}2017-12-13 \\
17: 01: 35\end{array}$ & $15.49 \mathrm{~V}$ & $66.33 \mathrm{~cm}$ & $\begin{array}{c}30.00 \\
\mathrm{C}\end{array}$ & 9.16 & 0.42 \\
\hline $\begin{array}{l}2017-12-13 \\
17: 01: 36\end{array}$ & $14.92 \mathrm{~V}$ & $77.96 \mathrm{~cm}$ & $\begin{array}{c}30.00 \\
\mathrm{C}\end{array}$ & 4.90 & 1.27 \\
\hline $\begin{array}{l}2017-12-13 \\
17: 01: 37\end{array}$ & $14.85 \mathrm{~V}$ & $83.77 \mathrm{~cm}$ & $\begin{array}{c}30.00 \\
\mathrm{C}\end{array}$ & 3.89 & 3.80 \\
\hline $\begin{array}{l}2017-12-13 \\
17: 01: 38\end{array}$ & $14.57 \mathrm{~V}$ & $90.75 \mathrm{~cm}$ & $\begin{array}{c}30.00 \\
\mathrm{C}\end{array}$ & 3.25 & 4.25 \\
\hline $\begin{array}{l}2017-12-13 \\
17: 01: 38\end{array}$ & $13.66 \mathrm{~V}$ & $104.68 \mathrm{~cm}$ & $\begin{array}{c}30.00 \\
\mathrm{C}\end{array}$ & 1.43 & 0.76 \\
\hline $\begin{array}{l}2017-12-13 \\
17: 01: 39\end{array}$ & $14.79 \mathrm{~V}$ & $111.66 \mathrm{~cm}$ & $\begin{array}{c}30.00 \\
\mathrm{C}\end{array}$ & 1.12 & 1.64 \\
\hline $\begin{array}{l}2017-12-13 \\
17: 01: 40\end{array}$ & $14.68 \mathrm{~V}$ & $112.85 \mathrm{~cm}$ & $\begin{array}{c}30.00 \\
\mathrm{C}\end{array}$ & 2.64 & 1.20 \\
\hline $\begin{array}{l}2017-12-13 \\
17: 01: 41\end{array}$ & $14.98 \mathrm{~V}$ & $110.52 \mathrm{~cm}$ & $\begin{array}{c}30.00 \\
\mathrm{C}\end{array}$ & 1.86 & 3.19 \\
\hline $\begin{array}{l}2017-12-13 \\
17: 01: 41\end{array}$ & $14.85 \mathrm{~V}$ & $110.52 \mathrm{~cm}$ & $\begin{array}{c}30.00 \\
\mathrm{C}\end{array}$ & 2.20 & 4.98 \\
\hline $\begin{array}{l}2017-12-13 \\
17: 01: 42\end{array}$ & $15.00 \mathrm{~V}$ & $117.50 \mathrm{~cm}$ & $\begin{array}{c}30.00 \\
\mathrm{C} \\
\end{array}$ & 0.60 & 4.55 \\
\hline $\begin{array}{l}2017-12-13 \\
17: 01: 43\end{array}$ & $14.98 \mathrm{~V}$ & $117.50 \mathrm{~cm}$ & $\begin{array}{c}30.00 \\
\mathrm{C}\end{array}$ & 1.12 & 4.66 \\
\hline $\begin{array}{l}2017-12-13 \\
17: 01: 43\end{array}$ & $13.93 \mathrm{~V}$ & $112.85 \mathrm{~cm}$ & $\begin{array}{c}30.00 \\
\mathrm{C}\end{array}$ & 0.45 & 4.38 \\
\hline $\begin{array}{l}2017-12-13 \\
17: 01: 44\end{array}$ & $14.92 \mathrm{~V}$ & $111.68 \mathrm{~cm}$ & $\begin{array}{c}30.00 \\
\mathrm{C}\end{array}$ & 0.46 & 6.15 \\
\hline $\begin{array}{l}2017-12-13 \\
17: 01: 45\end{array}$ & $15.30 \mathrm{~V}$ & $112.82 \mathrm{~cm}$ & $\begin{array}{c}30.00 \\
\mathrm{C}\end{array}$ & 0.21 & 3.80 \\
\hline $\begin{array}{l}2017-12-13 \\
17: 01: 46\end{array}$ & $14.77 \mathrm{~V}$ & $112.82 \mathrm{~cm}$ & $\begin{array}{c}30.00 \\
\mathrm{C} \\
\end{array}$ & 0.21 & 4.56 \\
\hline $\begin{array}{l}2017-12-13 \\
17: 01: 46\end{array}$ & $14.60 \mathrm{~V}$ & $111.66 \mathrm{~cm}$ & $\begin{array}{c}30.00 \\
\mathrm{C}\end{array}$ & 3.05 & 4.94 \\
\hline $\begin{array}{l}2017-12-13 \\
17: 01: 47\end{array}$ & $14.81 \mathrm{~V}$ & $114.01 \mathrm{~cm}$ & $\begin{array}{c}30.00 \\
\mathrm{C}\end{array}$ & 2.35 & 0.31 \\
\hline $\begin{array}{l}2017-12-13 \\
17: 01: 48\end{array}$ & $14.77 \mathrm{~V}$ & $115.17 \mathrm{~cm}$ & $\begin{array}{c}30.00 \\
\mathrm{C}\end{array}$ & 3.55 & 2.11 \\
\hline $\begin{array}{l}2017-12-13 \\
17: 01: 49\end{array}$ & $14.42 \mathrm{~V}$ & $115.15 \mathrm{~cm}$ & $\begin{array}{c}30.00 \\
\mathrm{C}\end{array}$ & 2.20 & 0.98 \\
\hline $\begin{array}{l}2017-12-13 \\
17: 01: 49\end{array}$ & $15.36 \mathrm{~V}$ & $115.15 \mathrm{~cm}$ & $\begin{array}{c}30.00 \\
\mathrm{C}\end{array}$ & 2.57 & 0.10 \\
\hline $\begin{array}{l}2017-12-13 \\
17: 01: 50\end{array}$ & $14.85 \mathrm{~V}$ & $115.15 \mathrm{~cm}$ & $\begin{array}{c}30.00 \\
\mathrm{C}\end{array}$ & 1.79 & 0.70 \\
\hline $\begin{array}{l}2017-12-13 \\
17: 01: 51\end{array}$ & $14.79 \mathrm{~V}$ & $113.98 \mathrm{~cm}$ & $\begin{array}{l}30.00 \\
\mathrm{C}\end{array}$ & 1.65 & 0.80 \\
\hline
\end{tabular}

\section{B. Pengujian Perangkat Kendali ROV}

Proses pengiriman instruksi oleh Joypad ke ROV menggunakan bahasa Pemrograman Python 2.7 dengan menambahkan dua library penting yakni Serial dan Socket. Fungsi dari library serial adalah untuk menangani proses penerimaan data serial yang dikirim oleh Arduino Pro Mini melalui Protokol USB. Sedangkan library socket bertujuan untuk menciptakan jalur komunikasi laptop dan Raspberry pada ROV agar laptop dapat mengirimkan instruksi oleh Joypad menuju Raspberry. Secara ringkasnya, listing program pada Gambar 7 bertujuan untuk mengirimkan instruksi oleh Joypad menuju Raspberry pada ROV agar dapat melakukan laju pergerakan ROV.

Tabel 3. Hasil pengujian perngiriman instruksi Joypad - Raspberry

\begin{tabular}{|c|c|c|}
\hline No & Tombol & Hasil Eksekusi Pada ROV \\
\hline 1 & Kotak & Bergerak Mundur \\
\hline 2 & Segitiga & Bergerak Turun \\
\hline 3 & Bulat & Bergerak Naik \\
\hline 4 & Silang & Bergerak Maju \\
\hline 5 & Panah Atas + Silang & Bergerak Maju dan Naik \\
\hline 6 & Panah Bawah + Silang & Bergerak Maju dan Turun \\
\hline 7 & Panah Kiri + Silang & $\begin{array}{l}\text { Bergerak Maju dan Belok } \\
\text { Kiri }\end{array}$ \\
\hline 8 & Panah Kanan + Silang & $\begin{array}{l}\text { Bergerak Maju dan Belok } \\
\text { Kanan }\end{array}$ \\
\hline 9 & Panah Atas + Kotak & Bergerak Mundur dan Naik \\
\hline 10 & Panah Bawah + Kotak & $\begin{array}{l}\text { Bergerak Mundur dan } \\
\text { Turun }\end{array}$ \\
\hline 11 & Panah Kiri + Kotak & $\begin{array}{lll}\text { Bergerak Mundur dan } \\
\text { Belok Kiri }\end{array}$ \\
\hline 12 & Panah Kanan + Kotak & $\begin{array}{l}\text { Bergerak Mundur dan } \\
\text { Belok Kanan }\end{array}$ \\
\hline 13 & $\mathrm{R} 1$ & Servo Bergerak Kanan \\
\hline 14 & $\mathrm{R} 2$ & Servo Bergerak Bawah \\
\hline 15 & L1 & Servo Bergerak Kiri \\
\hline 16 & L2 & Servo Bergerak Atas \\
\hline
\end{tabular}

Pengujian dilakukan pada kedalaman 1 sampai 4.2 meter. Pengendali laju pergerakan ROV ini terdiri dari 4 buah motor DC dan 2 buah motor servo sebagai plant,dengan relay module sebagai actuator,dan raspberry pi serta Arduino Pro Mini sebagai mikrokontroller yang digunakan dalam sistem perangkat kendali ini. Pada saat pengujian bawah air dilakukan, perangkat kendali telah mampu memberikan perintah yang dieksekusi dengan baik oleh module 
relay, sehingga ROV mampu bergerak sesuai dengan perintah operator. Gambar 9 cuplikan document asisaat ROV bergerakmaju.

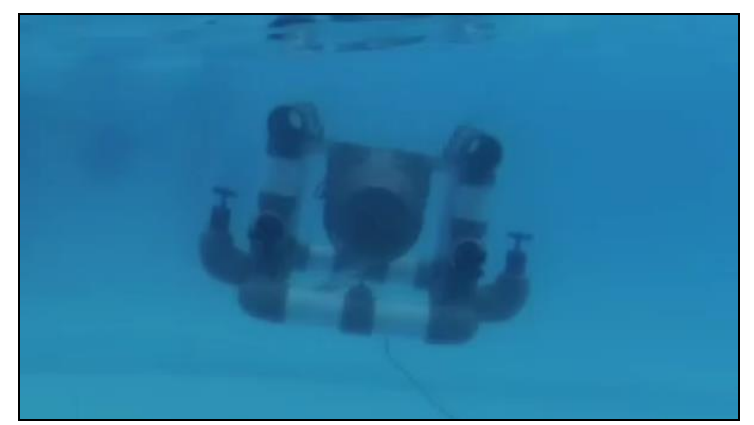

Gbr 10. ROV Bergerak Di Dalam Air

\section{KESIMPULAN}

Adapun kesimpulan dari penelitian ini adalah telah terealisasi system pengendali ROV yang dapat digunakan untuk mengendalikan pergerakan ROV dengan menggunakan Joypad. Aplikasi pemantauan kondisi bawah air dapat memantau kondisi bawah air secara realtime dan mengolah data yang berupa video streaming, data suhu, dan kedalaman ROV. Dari hasil pengujian diperoleh hasil yaitu perangkat kendali pergerakan ROV telah mampu mengendalikan laju pergerakan ROV untuk melakukan pergerakan turun, naik, belok kanan, belo kkiri, maju dan mundur. Tanpa adanya halangan pada kedalaman 0 sampai4,2 mete rmenggunakan Kabel LAN sepanjang 20 meter.

\section{REFERENSI}

[1].Anonim. (2016, September29). Arduino Pro Mini. Retrievied from https://www.arduino.cc/en/Main/arduino boardpromini. Arduino.

[2].Anonim. (2016, September 29). Raspberry Pi Foundation. Retrievied from http://www.raspberrypi.org/ Christ. Robert D., Wenli. Robert L. (2014). The ROV Manual A User Guide For Remotelt Operated Vehicle. Oxford: Elsefier.
[3].Handoko, Yeffri. (2013). Pemanfaatan Mini Pc Raspberry Pi Sebagai Pengontrol Jarak Jauh Berbasis Web Pada Rumah. Bandung. Universitas Komputer.

[4]. Rosmala, Dewi, dkk. (2012). Pembangunan Website

Contentmonitoringsystem Menggunakan Difflib Python. Bandung. Institut Teknologi Nasional

[5].Santoso, Berkah. (2012). Bahasa Pemrograman Python di Platform Gnu/Linux. Tangerang. Universitas Multimedia Nusantara

[6]. Souhoka Jemmy, Patty I Simon. (2013). Pemantauan Kondisi Hidrologi Dalam Kaitannya Dengan Kondisi Terumbu Karang Di Perairan Pulau Talise, Sulawesi Utara. Jurnal Ilmiah Platax. Vol 1.

[7].Zaenurrohman. Sutisna, Utis. (2014). Perancangan Sistem Kontrol Wireless pada Mobile Robot Manipulator Berbasis Mikrokontroler atmega8. Jogjakarta. Universitas Gajah Maa 